\title{
34
}

\section{The Self as a Point of Contact Between Social Psychology and Motivation}

Constantine Sedikides

Aiden P. Gregg

University of Southampton

nterdisciplinarity is a mixed blessing. An attempted union between two disciplines can cook up a couscous of conflicting assumptions and theories, misaligned methodological and data analytic strategies, and disconcertingly divergent validation philosophies. The chimerical offspring of this union will be amorphous, uncompelling, and unusable. Yet sometimes such a union can turn out to be a marriage made in heaven. The union of social psychology and motivation is a case in point, with the self as master of ceremonies.

The self acts as a methodological point of contact between contemporary social psychological and traditional motivational approaches. The former approach is nomothetic, experimental, and laboratory-based, whereas the latter is idiographic, naturalistic, and questionnaire-based. More importantly, the self acts as a theoretical point of contact between the two approaches. The role of the self as the facilitator of this doubly harmonious union is illustrated though a brief exposition to the self-evaluation literature.

\section{SELF-EVALUATION}

From Needs to Self-Eualuation Motives. Classic motivation research has graced the field of social psychology with such constructs as the need for uncertainty reduction (Weiner et al., 1971), the need for control (Rotter, 1966), the 
need to experience the self as an origin of action (deCharms, 1968), and the need for self-esteem (Rosenberg, 1965). These needs have been investigated by motivation researchers with the aid of targeted questionnaires. Their theoretical and empirical forays have had a profound impact on the self-evaluation literature, particularly in regard to the interplay between the individual and the social context. For example, what do people want to know about themselves? What kind of information are they most likely to solicit? What sort of feedback will they accept from others and how will they treat the person supplying it? How will they process and remember that feedback? Will that feedback influence their goal-setting and behavior?

Inspired by early motivation research on human needs, social psychologists set about addressing these questions in a generative manner. In the process, the concept of needs gave way to the concept of self-evaluation motives. Such motives were assumed to influence the way in which self-relevant information is selected, processed, remembered, or acted upon. Thus, the need for uncertainty reduction was reconceptualized in terms of the self-assessment motive; the need for control, in terms of the self-verification motive; the need to experience the self as an origin of action, in terms of the self-improvement motive; and the need for self-esteem, in terms of the self-enhancement motive (Sedikides \& Strube, 1997). Importantly, these reconceptualizations were complementary rather than antagonistic: The motives were assumed to result in need satisfaction.

More specifically, the self-assessment motive was proposed to guide the processing of self-relevant information so that the content of the self-concept (e.g., memories, judgments, behavioral sequelae) would be more accurate when judged by consensual or objective standards (Trope, 1986); the self-verification motive was proposed to direct self-relevant information processing in favor of the confirmation and validation of existing self-beliefs (Swann, 1983); the self-improvement motive was proposed to steer self-relevant information processing so as to raise levels of ability or performance and maximize potential for personality growth (Taylor, Neter, \& Wayment, 1995); and the self-enhancement motive was proposed to tilt self-relevant information processing in favor of a positive self-concept (Brown \& Dutton, 1995).

Social psychology's appropriation of these theoretical constructs was a breath of fresh air. The motives were construed as dynamic, intraindividual variables that could readily lend themselves to laboratory experimentation. Accordingly, three research vistas opened up, each revolving around a key question. First, is each motive influential in its own right? This question was answered in the affirmative: Each of the four motives was shown to affect selfrelevant information processing in substantive ways. Second, although the motives could and did coexist, what happened when they are in an antagonistic relation? In several programs of research, one motive was pitted against the other. Although we do not claim to be utterly dispassionate reviewers of the available literature (no doubt, being swayed by self-motives of our own!), we believe that the available evidence suggests that, all things considered, the 
self-enhancement motive is preeminent (Sedikides \& Gregg, 2003). Third, and perhaps most importantly, what are the circumstances under which one motive prevails over another? A plethora of research has addressed this question. It has been shown, for example, that despite the general primacy of self-enhancement, (a) self-assessment prevails over self-enhancement when the self is evaluated on well-defined and verifiable attributes as opposed to ill-defined and unverifiable ones, (b) self-improvement prevails over self-enhancement on personality dimensions viewed as modifiable as opposed to fixed, and (c) self-verification prevails over self-enhancement when cognitive resources are plentiful as opposed to scarce (Baumeister, 1998; Sedikides \& Strube, 1997).

\section{FROM APPROACH/AVOIDANCE TO SELF-ENHANCEMENT/SELF-PROTECTION}

The uxorious union of classic motivation and contemporary self-evaluation approaches has given birth to another bouncing baby. Classic motivation research introduced the idea of the approach/avoidance dimension, inspired by the fact that behavior in achievement settings is oriented either toward the pursuit of success (approach) or the flight from failure (avoidance) (McClelland, Atkinson, Clark, \& Lowell, 1953; Murray, 1938). Modern selfevaluation research has reconceptualized this dimension in terms of self-promotion versus self-protection, the yin and yang of self-enhancement. The former refers to the proactive attempt to positively affirm the self, and the latter to the defensive attempt to prevent devaluation of the self.

This reconceptualization provided impetus for investigating the self-protection motive. An impressive amount of research has now documented that humans are motivated to protect the self against threat. Humans treat the self as priceless possession, guard it vigilantly, protect it with zeal and vigor. For example, they deny their shortcomings, displace blame for their failures, react angrily to unfavorable feedback and recruit compensatory qualities to offset it, change the meaning of their negative self-aspects to give them a more positive spin, and strategically compare themselves to less fortunate others (Sedikides \& Gregg, 2003). In fact, humans are averse to negative self-relevant feedback even when it is accurate (Sedikides, 1993), and remember such feedback poorly (Sedikides \& Green, 2000) even when the feedback is consistent with their negative characteristics. That is, in direct tests, the self-protection motive has trumped the self-assessment and self-verification motives.

Classic motivation research has concerned itself with the relative potency of the approach versus avoidance motive, treated as an individual-difference variable (McClelland et al., 1953). In contrast, self-evaluation research has conceptualized the self-promotion and self-protection motives as intraindividual variables (but also as an individual-difference variable; Tice, 1991) while asking the same question about relative potency. The ensuing research revealed that self-protection is, on the whole, more powerful than self-pro- 
motion: Humans are more strongly motivated to protect the self against threatening feedback than to use feedback to boost the positivity of the self (Baumeister, Bratslavsky, Finkenauer, \& Vohs, 2001).

\section{FROM EXPLICIT TO IMPLICIT SELF-EVALUATION}

Classic motivation research has distinguished between implicit and explicit motives (McClelland et al., 1953; McClelland, Koestner, \& Weinberger, 1989). Explicit motives were considered cognitive representations of one's values, developed through verbally transmitted socialization experiences, and predictive of deliberate choices. Implicit motives, on the other hand, were thought to be affective associative structures, developed through preverbal socialization experiences, and predictive of spontaneous or habitual responses.

This distinction has once again been transmuted in self-evaluation research. Explicit self-evaluation motives are accessible to conscious awareness and are assessed through questionnaires. However, implicit motives are inaccessible to conscious awareness and are assessed through indirect or unobtrusive tests such as the Implicit Association Test (indexing automatic associations between self and valence; Greenwald, McGhee, \& Schwartz, 1998) or the Name-Letter Effect (estimating participants' preference for letters in their own name; Nuttin, 1985). Implicit measures are credited for some of the most exciting, if controversial, developments in self-evaluation research. For example, use of these measures has documented the universalism of self-enhancement: This motive is equally prevalent in Western and Eastern culture (Hetts, Sakuma, \& Pelham, 1999).

\section{CONCLUSIONS}

We began this chapter by claiming that the union of two disciplines is not necessarily a happy one. In fact, we are prone to believe that interdisciplinarity, like marriage, has only a $50 \%$ chance of succeeding.

We have chosen, however, to tell a success story: the influence of classic motivation research on contemporary self-evaluation research. We highlighted three domains of such influence. The first involves the reconceptualization of crucial human needs in terms of self-evaluation motives. The second involves the reconceptualization of the approach/avoidance dimension in terms of the self-promotion/self-protection dimension. The final one involves the reconceptualization of implicit versus explicit motives in terms of implicit versus explicit self-evaluations. In all three domains, substantial theoretical developments have resulted in methodological innovation, just as happy marriages produce healthy children.

Of course, these three domains are not the only instances of interdisciplinary fertilization. The field of self-evaluation has been influenced by philosophical theorizing, and advances in cognitive, developmental and health psychology, as well as trends in personality and cultural psychology (Sedikides 
\& Gregg, 2003; Sedikides \& Strube, 1997). Nevertheless, we believe that the interdisciplinary success of classic motivation and self-evaluation research can serve as a concrete example for additional bridge-building between motivation and social psychology. Also, we hope that this scholarly influence will increasingly become bidirectional in nature, as the maturing of self-evaluation research will have theoretical and methodological implications for motivation research.

\section{REFERENCES}

Baumeister, R. F. (1998). The self. In D. T. Gilbert, S. T. Fiske, \& G. Lindzey (Eds.), The handbook of social psychology (Vol. 1, pp. 680-740). New York: Oxford University Press.

Baumeister, R. F., Bratslavsky, E., Finkenauer, C., \& Vohs, K. D. (2001). Bad is stronger than good. Review of General Psychology, 5, 323-370.

Brown, J. D., \& Dutton, K. A. (1995). Truth and consequences: The cost and benefits of accurate self-knowledge. Personality and Social Psychology Bulletin, 21, $1288-1296$.

deCharms, R. (1968). Personal causation: The internal affective determinants of behavior. New York: Academic Press.

Greenwald, A. G., McGhee, D. E., \& Schwartz, J. L. K. (1998). Measuring individual differences in implicit cognition: The implicit association test. Journal of Personality and Social Psychology, 74, 1464-1480.

Hetts, J. J., Sakuma, M., \& Pelham, B. W. (1999). Two roads to positive self-regard: Implicit and explicit self-evaluation and culture. Journal of Experimental Social Psychology, 35, 512-559.

McClelland, D. C., Atkinson, J. W., Clark, R. A., \& Lowell, E. L. (1953). The achievement motive. New York: Appleton-Century-Crofts.

McClelland, D. C., Koestner, R., \& Weinberger, J. (1989). How do self-attributed and implicit motives differ? Psychological Review, 96, 690-702.

Murray, H. (1938). Explorations in personality. New York: Oxford University Press.

Nuttin, J. M. (1985). Narcissism beyond gestalt and awareness: The name letter effect. European Journal of Social Psychology, 15, 353-361.

Rosenberg, M. (1965). Society and the adolescent self-image. Princeton, NJ: Princeton University Press.

Rotter, J. B. (1966). Generalized expectancies for internal versus external control . of reinforcement. Psychological Monographs, 80(1, Whole No. 609).

Sedikides, C. (1993). Assessment, enhancement, and verification determinants of the self-evaluation process. Journal of Personality and Social Psychology, 65, 317-338.

Sedikides, C., \& Green, J. D. (2000). On the self-protective nature of inconsistency/negativity management: Using the person memory paradigm to examine self-referent memory. Journal of Personality and Social Psychology, 79, 906-922.

Sedikides, C., \& Gregg, A. P. (2003). Portraits of the self. In M. A. Hogg \& J. Cooper (Eds.), Sage handbook of social psychology (pp. 110-138). London: Sage.

Sedikides, C., \& Strube, M. J. (1997). Self-evaluation: To thine own self be good, to thine own self be sure, to thine own self be true, and to thine own self be better. In M. P. Zanna (Ed.), Advances in experimental social psychology (Vol. 29, pp. 209-269). New York: Academic Press. 
Swann, W. B., Jr. (1983). Self-verification: Bringing social reality into harmony with the self. In J. Suls \& A. G. Greenwald (Eds.), Psychological perspectives on the self (Vol. 2, pp. 33-66). Hillsdale, NJ: Lawrence Erlbaum Associates.

Taylor, S. E., Neter, E., \& Wayment, H. A. (1995). Self-evaluation processes. Personality and Social Psychology Bulletin, 21, 1278-1287.

Tice, D. M. (1991). Esteem protection or enhancement? Self-handicapping motives and attributions differ by trait self-esteem. Journal of Personality and Social Psychology, 60, 711-725.

Trope, Y. (1986). Self-enhancement and self-assessment in achievement behaviour. In R. M. Sorrentino \& E. T. Higgins (Eds.), Handbook of motivation and cognition: Foundations of social behavior (Vol. 1, pp. 350-378). New York: Guilford Press.

Weiner, B., Frieze, I., Kukla, A., Read, C., Rest, S., \& Rosenbaum, R. M. (1971). Perceiving the causes of success and failure. Morristown, NJ: General Learning Press. 